\title{
EDUCAÇÃO ALIMENTAR E NUTRICIONAL ENQUANTO PROCESSO EDUCATIVO: UM ESTUDO DE PRÁTICAS E PERCEPÇÕES DE UMA COMUNIDADE ESCOLAR DE UBERABA-MG
}

\author{
EDUCACIÓN ALIMENTARIA Y NUTRICIONAL COMO PROCESO EDUCATIVO: \\ UN ESTUDIO DE PRÁCTICAS Y PERCEPCIONES DE UNA COMUNIDAD \\ ESCOLAR EN UBERABA - MG
}
FOOD AND NUTRITIONAL EDUCATION AS AN EDUCATIONAL PROCESS: A STUDY OF PRACTICES AND PERCEPTIONS OF A SCHOOL COMMUNITY FROM UBERABA-MG

Ralph CASTRO ${ }^{1}$

RESUMO: Este artigo tem como tema a Educação Alimentar e Nutricional (EAN) no espaço escolar, está vinculado à linha de pesquisa "Processos Educacionais e seus Fundamentos", do Programa de Pós-graduação em Educação da Universidade de Uberaba. A pesquisa inicia com a seguinte questão: como é trabalhada e quais espaços a EAN ocupa no cotidiano de uma escola municipal considerada como modelo da cidade Uberaba, MG? Tendo como objetivo geral compreender os limites e as possibilidades da EAN no ensino fundamental. Participaram crianças, professores, funcionários e familiares da comunidade escolar. Constatou-se, em campo, que a contribuição da escola na EAN se reduz à oferta de merenda saudável, e, que para alguns adultos, o interesse das crianças por alimentos artificiais e industrializados é uma característica inata. Conclui-se que mesmo a EAN não sendo trabalhada na escola, existem espaços onde isso pode se dar - e que não se limitam à sala de aula.

PALAVRAS-CHAVE: Educação alimentar e nutricional. Educação básica. Empoderamento.

RESUMEN: Este artículo presenta como tema la Educación Alimentaria y Nutricional (EAN) en el espacio escolar, está relacionado a la línea de investigación "Procesos Educacionales y sus Fundamentos", del Programa de Posgrado en Educación de la Universidad de Uberaba. La búsqueda empieza con la cuestión: Como es trabajada y cuales son los espacios que ocupa la EAN en el cotidiano de una escuela municipal considerada referencia de la ciudad de Uberaba, MG? Tomando como objetivo general compreender los límites y las posibilidades de la EAN en la enseñanza fundamental. Participaron niños, maestros, empleados y familiares de la comunidade escolar. Se observó, en campo, que la contribución de la escuela en la EAN al ofrecimiento de una merienda sana, y, que para algunos adultos, el interés de los niños por alimentos artificiales e industriales es una característica innata. Se concluye que mismo la EAN

1 Universidade de Uberaba (UNIUBE), Uberaba - MG - Brasil. Departamento de Pós-graduação Mestrado em Educação (UNIUBE). Nutricionista graduado em 2002, Mestre em Educação pelo Mestrado de Educação (UNIUBE), com pós-graduação Latu Senso em Docência Universitária (UNIUBE). ORCID <http://orcid.org/0000-0003-2570-8673>.E-mail: ralphsportnut@ terra.com.br 
no siendo trabajada en la escuela, existen espacios donde eso puede darse - y que no se limitan a un aula escolar.

PALABRAS CLAVE: Educación alimentaria. Educación básica. Empoderamiento.

ABSTRACT: This paper, which has the Food and Nutrition Education (FNE) theme in the school premises, is linked to the "Educational Processes and their Fundamentals" research line, from the Uberaba University Postgraduate Program in Education. This research starts with the following question: how is it worked and what spaces does FNE occupy in the daily life of a City School considered as model of the city of Uberaba, $M G$ ? Its general objective is to understand the limits and possibilities of FNE in elementary education. Participants in the survey were children, teachers, school staff and family members of the school community. It was found that the school's contribution to FNE is reduced to the supply of healthy snacks and that for some adults, children's interest in artificial and industrialized food is an innate feature. It is concluded that even the FNE not being worked on in the school, there are spaces where this can be given - and those are not limited to the classroom alone.

KEYWORDS: Food and nutritional education. Basic education. Empowerment.

\section{Introdução}

Vinculada à linha de pesquisa "Processos Educacionais e seus Fundamentos", do Programa de Pós-graduação em Educação (Metrado em Educação) da Universidade de Uberaba, este artigo resulta de um projeto de pesquisa acadêmica sobre Educação Alimentar e Nutricional (EAN), realizada em uma comunidade escolar da cidade de Uberaba, MG.

A proposta deste estudo parte da constatação de que, atualmente, muitas crianças passam mais tempo na escola do que com os próprios pais, não sendo raro encontrarmos famílias em que os pais dedicam mais tempo ao trabalho que à família. Considerando que sendo a alimentação uma necessidade básica e fundamental, caberia também à escola sensibilizar a comunidade para a importância da alimentação saudável e sua relação com a saúde e qualidade de vida.

Assim, ao findar este estudo, pretendemos contribuir para o entendimento de que à escola não cabe apenas "oferecer" ao aluno refeições balanceadas. Sua função formadora exige desta instituição que se comprometa também com a construção de saberes e práticas pelas quais a comunidade escolar - e não apenas o alunado - possa reconhecer-se em seu protagonismo político, o que, em um contexto marcado pela 
diversidade, também ocorre quando são ouvidos e valorizados hábitos alimentares distintos, e, ao mesmo tempo, incentivadas práticas que elevem a qualidade de vida.

Por comunidade escolar, estamos nos referindo a um conjunto de relações e de sujeitos que inclui direção ou gestão, professores, funcionários, alunos, pais e/ou responsáveis, outros familiares, parceiros e, em alguns casos, especialistas que atuam continuamente na escola. (FREIRE, 2004).

Neste sentido, considerando como uma das finalidades da educação a promoção da autonomia, discutir os limites e as possibilidades da Educação Alimentar e Nutricional, no ensino fundamental, verificando se esta pode se legitimar como um processo educativo emancipatório, parece ser um importante passo no sentido de formar sujeitos críticos (com autonomia para decidir conscientemente, apesar do excesso de informação e das imposições de mercado e mídia em relação à alimentação) saudáveis e capazes de decidir o que é melhor para si e para o coletivo. Para Gramsci (2002), defensor de uma escola unitária ou humanista, a instituição de ensino deveria articular teoria e prática, unificando-as na práxis com vistas à transformação da realidade social.

Neste sentido, Fiori (1992), defende que as instituições de ensino devem promover a conscientização do processo cultural, tornando-se centros conscientes de elaboração e renovação cultural e de todas as suas práticas. Para Freire (1987), as instituições de ensino deveriam promover a valorização e a conscientização de uma cultura do autocuidado. E para Boog (1999) numa escola apta a contribuir para a emancipação dos sujeitos e a transformação social, a educação alimentar e nutricional, da qual deve fazer parte a discussão dos significados e sentidos da alimentação, ocupa um papel de destaque no quadro de iniciativas necessárias para a melhoria do presente e do futuro da sociedade brasileira.

Para pensar na relevância deste estudo, primeiro precisamos considerar a alimentação como um pré-requisito básico, assim como respirar ou dormir. Em seguida é preciso ir além do conceito de ração balanceada. No ritual de preparo e consumo da comida nós humanos reafirmamos nossa identidade, valorizamos nossa cultura, celebramos a comunhão, criamos, amamos, expressamos nosso carinho, solidariedade, espiritualidade e religiosidade. A vida agitada do capitalismo urbano-industrial promove a busca por alimentos industrializados (rápidos e práticos), concentrando o capital nas mãos das grandes empresas e corporações e promovendo, ao mesmo tempo, um impacto negativo na saúde das pessoas. Neste contexto, a EAN adquire uma relevância, não apenas no que diz respeito à alimentação saudável, mas na direção de transformar a 
nação. A soberania de um país, a dignidade de um povo tem como primeiro passo garantir a alimentação saudável (VALENTE, 2002).

\section{EAN: um estudo do estado da arte}

Segundo informação obtida no Portal de Periódicos da CAPES, nos últimos dez anos foram publicados, no Brasil, 52 artigos que têm como assunto a expressão exata "Educação Alimentar e Nutricional". Analisando os resumos o que constatamos, contudo, foi que poucos destes textos voltam-se à EAN na educação escolar. A maior parte dos 52 estudos publicados por 17 periódicos é das áreas de ciências biológicas e da saúde. E, o que chama mais nossa a atenção: nenhum deles foi publicado em periódico da área de educação.

Ainda no mesmo banco de dados, utilizando a opção "todos os campos", da busca avançada, foram encontrados 20 estudos que trazem exatamente o termo Educação Alimentar e Nutricional, divididos nas seguintes áreas do conhecimento: cinco pesquisas de enfermagem; quatro produções da área de ensino de ciências e matemática; três trabalhos de nutrição; três estudos de pediatria; um da área de administração; um da área de cardiologia; uma da área de saúde coletiva; um da área de saúde e biológicas e um estudo da área de educação.

Ainda utilizando como fonte de pesquisa o Banco de Teses da CAPES, iniciouse a busca por trabalhos que contivessem os termos "Educação Alimentar" e "Ensino Fundamental" em seus resumos. Como resultados, foram encontrados cinco trabalhos, todos eles dissertações de mestrado defendidas após 2010. Em continuidade, o segundo descritor foi substituído pelo termo "Escola", resultando, assim, em onze produções. Ao final, este descritor foi novamente substituído, desta vez pelo termo "Educação Básica", para o qual não obtivemos nenhum resultado.

Ao alterar o primeiro descritor para "Educação Alimentar e Nutricional", mantendo o cruzamento com "Ensino Fundamental", o número de produções foi reduzido a três dissertações: uma da área de administração, uma de ensino em ciências e matemática e uma de ciências biológicas. Em cruzamento com "Escola" surgiram sete dissertações e, com "Educação básica", novamente nenhum trabalho foi apontado. Considerando que estas seriam as dissertações de mestrado e teses defendidas no Brasil nos últimos dez anos, sobre o tema, o quadro nos permite ponderar que a área da 
Educação ainda está pouco envolvida com a discussão da EAN, o que reforça a relevância da pesquisa aqui apresentada.

Em um total de 46 trabalhos que apareceram utilizando todos os descritores, apenas quatro referem-se a pesquisas específicas da área de Educação. Também merece destaque o fato de que, entre todos os trabalhos, 24 estudos propõem-se a discutir EAN e Educação Alimentar a partir de ciências das ciências biológicas e da saúde (nutrição, enfermagem, pediatria, cardiologia, saúde coletiva). Isto demonstra uma hegemonia da visão biomédica sobre a alimentação e nutrição que, sabidamente, são fenômenos transdisciplinares. Em apenas três dissertações que debatem o tema EAN na escola os autores apontam para a necessidade de se investir na formação de professores para trabalhar com essa temática.

Utilizando outra base de pesquisa, a Biblioteca Digital Brasileira de Teses e Dissertações (BDTD), foi feita uma seleção de estudos, nos últimos dez anos que continham os termos "Educação Alimentar e Nutricional" e "Ensino Fundamental" em todos os campos e foram encontrados 25 estudos, sendo 21 dissertações e quatro teses. Destes trabalhos a grande maioria trata de temas como: estado nutricional de crianças e adolescentes nas escolas; análise da alimentação, dos alimentos comercializados e da composição de nutrientes da merenda escolar; promoção da saúde; álcool e tabaco dentre outros temas. Apenas sete trabalhos discorrem sobre EAN nas escolas, sendo cinco dissertações e duas teses.

Com vistas a encontrar mais estudos sobre o tema a ampliar o horizonte teórico, realizamos outro levantamento, utilizando a mesma base, a Biblioteca Digital Brasileira de Teses e Dissertações (BDTD). Buscando estudos contendo os termos "Ensino Fundamental" e "Educação Nutricional" em todos os campos, foram encontrados 42 resultados referentes a trabalhos defendidos nos últimos dez anos. Em síntese: mais da metade dos estudos não discutem as possibilidades da EAN no ambiente escolar. A EAN, na maioria dos trabalhos, é apontada como uma maneira de se combater a obesidade, ou alcançar um nível adequado de nutrientes, ou ainda como uma das formas de se atingir um bom desempenho escolar principalmente associada a atividades física.

A princípio, chama a atenção que em sete trabalhos os autores concluam que a questão está diretamente relacionada à necessidade de maiores investimentos na formação de professores. Outro ponto importante aparece em pelo menos quatro trabalhos é a pouca participação da comunidade escolar. De fato, é muito difícil, principalmente para uma criança, desenvolver bons hábitos sem o apoio da família e dos 
adultos que a rodeiam. Em três trabalhos os autores sugeriram que a EAN deveria fazer parte do projeto político pedagógico, do conteúdo didático dado em sala. Em um trabalho a autora chegou à conclusão que os alunos pesquisados não tinham conhecimento suficiente para ler e entender rótulos de alimentos, e noutra pesquisa o autor relata que a oratória foi a principal maneira de trabalhar a EAN.

Tudo isso chama atenção novamente para o uso de atividades práticas para abordar o tema. Considerando que, durante séculos, as pessoas aprenderam a preparar e ingerir seus alimentos através da prática, apenas aulas, palestras e informações sobre o teor de nutrientes dos alimentos pode não ser suficiente para trabalhar a EAN na escola. Muito se critica o consumo de comida pronta, rápida e industrializada, mas qual é a saída para quem não sabe preparar seu alimento? Em todos os trabalhos apenas duas escolas realizaram com seus alunos atividades práticas envolvendo a manipulação de alimentos.

Em muitos municípios, as escolas têm merenda terceirizada, o que significa dizer em muitos casos que a cantina é o espaço do "outro", o que dificulta a entrada de alunos e professores para a utilização do espaço pedagogicamente. Além disso, contribui para dificultar o trabalho de EAN nas escolas à presença de estruturas precárias de cantinas em várias escolas no Brasil. Alguns trabalhos defendem a contratação de técnicos especializados e a participação do nutricionista nas ações de EAN, porém, apontam que a própria formação do nutricionista, assim como de outros profissionais, apresenta inúmeras lacunas. Grande parte dos cursos de nutrição do país dedicam poucas horas ao ensino de EAN, a maior parte da formação é voltada ao estudo dos nutrientes e suas ações na biologia humana.

Porém, o fato que mais chama atenção é que a maioria dos trabalhos não pertence à área da Educação e sim da área da saúde. Perpetuando mais uma vez a visão do alimento como fonte de nutriente e não como comida, cultural e histórica. Essa realidade aparece claramente nos trabalhos quando se observa que a maioria deles trata de questões técnicas e de conhecimentos sobre os alimentos, pouco se discute no sentido de planejar a melhor forma de ensinar a EAN para a comunidade escolar.

$\mathrm{O}$ estudo do estado da arte a respeito da temática EAN permite concluir que a alimentação precisa ser entendida de forma mais ampla, o que inclui a necessidade de contribuições e outras áreas como a área da educação. Na mesma linha, também é preciso que outros profissionais, não apenas os com formação em saúde, participem no planejamento, elaboração, execução e avaliação das atividades de EAN na comunidade 
escolar.

\section{A alimentação escolar na cidade de Uberaba}

Constam no Plano Nacional de Segurança Alimentar e Nutricional seis metas prioritárias para o período entre 2012 e 2015, entre elas "promover ações de Educação Alimentar e Nutricional no ambiente escolar" (BRASIL, 2011).

Em Uberaba, a lei 8.931 de 15 de outubro de 2003 instituiu o Programa Municipal de Educação Alimentar e Nutricional (PMEAN) entendido como um processo para transformação das práticas alimentares dos alunos, segurança alimentar, promoção da saúde e melhoria da qualidade de vida. No Art. $2^{\circ}$ consta:

O Programa consiste no atendimento coletivo das escolas municipais em termos de higiene ambiental, pessoal e dos alimentos, bem como o atendimento na questão da elaboração de cardápios, palestras sobre alimentação saudável abrangendo pais, educadores, profissionais de saúde em atividades de higiene e educação nutricional com os alunos, com meta a promover o bem-estar físico, nutricional e contexto profilático (UBERABA, 2003).

Neste artigo é possível perceber uma concepção de EAN feita através da transmissão de informação, utilizando entre outras estratégias palestras e atividades de higiene. $\mathrm{O}$ Art. $3^{\circ}$ da mesma lei determina a coordenação do PMEAN para uma equipe técnica composta por profissionais da área de saúde como nutricionistas, especialistas em nutrição humana e saúde, técnicos em nutrição, médico, psicólogo e professores de Educação Física. Neste artigo é possível perceber o mesmo fenômeno que ocorre na produção acadêmica a respeito do tema EAN: a forte influência da área biomédica (UBERABA, 2003).

Em Uberaba, o Conselho de Alimentação Escolar (CAE) passou a ser vigente em Medida Provisória - MP no 2178-36, de 24 de agosto de 2000. O CAE é um órgão ligado às Entidades Executoras do Programa Nacional de Alimentação Escolar (PNAE), que existe para fiscalizá-las, acompanhá-las e assessorá-las na utilização dos recursos financeiros transferidos pelo Fundo Nacional de Desenvolvimento da Educação (FNDE). O CAE é composto por sete membros titulares, representantes de diversos segmentos, entre eles, pais de alunos e professores, o CAE deve zelar pela qualidade da alimentação escolar oferecida aos alunos. 
Em consulta a atas do $\mathrm{CAE}^{2}$ da cidade de Uberaba, há o registro que, no final de agosto de 2006, foi assinado um contrato com a empresa Nutriplus, de Salto SP. Neste contrato ficou estabelecido que a empresa passasse a prestar serviços no preparo da merenda escolar. Desta forma, a merenda escolar passou a ser fornecida pela empresa em setembro de 2006, o que prossegue até os dias atuais.

A gestão não terceirizada do processo permitiria um maior controle e autonomia do município para gerir e decidir os rumos e a filosofia do trabalho, como, por exemplo, utilizar as cantinas também como um espaço de ensino-aprendizagem. A gestão terceirizada parece aliviar a burocracia dos processos de fornecimento, armazenamento, aquisição e preparo, uma vez que a Prefeitura adquire aspecto, sobretudo, de fiscalizadora. Porém, inviabiliza o desenvolvimento de projetos de EAN e de uso da cantina ou cozinha como espaço de aprendizagem. Com a terceirização, este espaço está na escola, mas não é da escola, tornando-se, assim, um espaço do "outro", protegido contratualmente. Uma solução seria prever, em futuras renovações de contrato, espaços para realização de atividades práticas periódicas e sistemáticas de EAN dentro das escolas, caso a educação para a mudança de hábitos e qualidade de vida seja realmente uma filosofia a ser considera, e não apenas idealizada, pela administração pública municipal.

\section{Percurso metodológico e processo de pesquisa}

Considerando que cabe à escola ir além de "matar a fome" e oferecer uma merenda balanceada, e, que através da participação social, a escola deve promover a autonomia e o entendimento da relação entre alimentação saudável, saúde e a qualidade de vida. A questão condutora do estudo é: como é trabalhada e quais espaços a Educação Alimentar e Nutricional ocupa no cotidiano da comunidade escolar de uma escola municipal considerada como modelo, da cidade de Uberaba, MG?

A partir dessa questão, estabelecemos como objetivo geral compreender os limites e as possibilidades da Educação Alimentar e Nutricional, no ensino fundamental, verificando se esta pode se legitimar como um processo educativo emancipatório.

A investigação realizada neste trabalho envolveu um estudo do estado da arte de todo o referencial teórico e pesquisa de campo, esta última foi realizada a partir do que

${ }^{2}$ As atas consultadas, referentes a reuniões do Conselho de Alimentação Escolar (CAE) do município de Uberaba ocorridas entre 2004 e 2016, foram gentilmente cedidas ao pesquisador pela Secretária de Educação do Município de Uberaba. Prf ${ }^{a}$ Diretora da Diretoria de Ensino Sônia Manzan. 
Lüdke e André (1986) chamam de "pesquisa de tipo etnográfico", que consiste na adaptação de procedimentos da etnografia, exigindo, do pesquisador, um constante movimento de construção e reconstrução (de acordo com o desenrolar da pesquisa) das bases teóricas, das estratégias de coleta de dados e do "esquema" de trabalho. O objetivo desse tipo de pesquisa é apreender o modus vivendi e compreender os sentidos que a ele são atribuídos pelos sujeitos (MÁRQUES, 2016). A opção por desenvolver a pesquisa de tipo etnográfico nos leva ao encontro da abordagem qualitativa, que, conforme síntese apresentada por Abreu-Bernardes et. al. (2013, p.135), teria como características centrais: a observação e o esforço descritivo, a preocupação com o processo e não apenas com o produto e a busca do significado das situações para os sujeitos.

Assim, os sujeitos dessa pesquisa organizam-se nos seguintes grupos: dezenove (19) alunos participantes (dez alunos da turma de seis anos de idade, e nove alunos da turma de dez anos de idade); quatro (4) professores (dois professores de cada turma); treze (13) pais e/ou responsáveis (seis responsáveis por crianças de seis anos e sete pais e/ou responsáveis por alunos de dez anos); quatro (4) funcionários de áreas diversas (administração, limpeza e outros).

Além de serem observados em atividades do cotidiano escolar, os alunos das duas turmas disponibilizadas pela direção da escola responderam a um instrumento misto contendo ilustrações e frases concisas (evidentemente que levando em conta o nível de compreensão da linguagem escrita), sobre os temas: educação, alimentação e saúde.

Depois de transcritas, as entrevistas concedidas pelos adultos receberam o mesmo tratamento que os dados obtidos a partir do instrumento aplicado às crianças: optamos pela análise de conteúdo, que ficou muito conhecida a partir do trabalho de Bardin (1977).

Em relação ao locus da pesquisa a cidade conta com aproximadamente 70 unidades de ensino municipais, entre escolas municipais e CEMEIs - Centros Municipais de Educação Infantil (UBERABA, 2016). A escola em que se deu a pesquisa está localizada na divisa de dois bairros periféricos da cidade e atende a um público heterogêneo quanto às condições socioeconômicas e culturais. Como se trata de uma escola apresentada pela administração pública municipal como "escola modelo", além de atender a crianças da região, a instituição tem sido cada vez mais procurada famílias que não tem mais condições de arcar com os custos do ensino privado. $\mathrm{O}$ fato de se tratar de uma escola modelo sugere que as ações educativas ali desenvolvidas 
estejam mais próximas daquilo que, na Secretaria Municipal de Educação (SEMED), é reputado como um ideal a ser alcançado (ABREU-BERNARDES, 2013).

\section{Considerações finais}

Apesar do número reduzido de participantes e de se tratar de membros de apenas uma comunidade escolar, os dados apresentados neste estudo, assim como suas considerações não tem a intenção de generalizar, mas sim, de apontar para um aspecto da realidade, Todavia, nada impede que as constatações deste estudo encontrem concordância em outras comunidades escolares, sobretudo naqueles com baixo poder aquisitivo.

A EAN pode ser uma estratégia bem aceita pelos alunos que participaram desta pesquisa, dado o interesse principalmente dos mais jovens, em conhecer novos alimentos e saber preparar sua própria comida. Porém, considerando a observação de campo e a fala dos participantes é possível dizer que pelo menos uma das abordagens destinada a EAN (não há indícios que existe outra), ocorre à luz de um conceito ultrapassado de saúde, ainda fundamentado na lógica biomédica, onde a saúde é entendida como ausência de doença. $\mathrm{O}$ que foi reforçado na fala das crianças e dos adultos ao associarem a determinados alimentos o valor de ser "bom" ou "ruim" para a saúde, podendo ser consumidos "muito" caso faça "bem" para saúde, e, "pouco" caso faça "mal" para saúde. Além disso, algumas crianças e adultos relacionam a determinados alimentos como fontes de nutrientes específicos, o que reforça a ideia de alimento apenas como fonte de nutriente, destinado a combater ou impedir algum processo patológico, desconsiderando todo valor social e cultural da comida.

Tanto para os adultos quanto as crianças deste estudo é possível identificar um distanciamento entre o discurso e a prática, a décalage, apontada no estudo de Castro (2015). Este distanciamento pode ser fruto, especialmente para as crianças que participaram desta pesquisa, do fator gosto, o paladar, associado a um alimento pode interferir de maneira decisiva na decisão da criança. Ou seja, no momento de escolher e consumir um alimento (prática), a criança e também alguns adultos, pode optar pelos alimentos que agradam mais seu paladar, apesar, de saber (discurso) que aquele alimento não trará benefícios à sua saúde.

Analisando a forma como a EAN foi trabalhada com os alunos na escola é possível perceber a importância de investir na culinária, de forma a tornar os alimentos 
saudáveis mais saborosos, favorecendo o maior consumo dos mesmos, ou seja, aproximando o discurso da prática descrito no parágrafo acima. Além disso, para estas crianças o contexto em que se come o vínculo social, a confraternização também é importante na hora de alimentar. Isso reforça a necessidade de promover atividades coletivas de cultivo, preparo e degustação para promover vínculo, e o sentimento de pertencer e de identidade com a comunidade escolar.

Especialmente sobre a opinião dos adultos participantes foi possível perceber, entre a maior parte deles, opiniões contraditórias sobre o dever da escola de ajudar na formação dos hábitos alimentares dos alunos. Para a maior parte dos pais e/ou responsáveis a escola poderia contribuir impedindo a venda de lanche, proibindo o aluno de levar lanche de casa (o que também é responsabilidade dos pais) e melhorando o cardápio da escola (apesar de alguns pais não saberem o que é servido às crianças). A maior parte dos professores e funcionários relatou que a escola não contribuiria de maneira decisiva na formação dos hábitos alimentares dos alunos, uma vez que a educação feita em casa seria o principal fator. Uma lógica semelhante a da primeira metade do século passado, onde cabia a escola apenas fornecer a merenda. Apesar de pais e/ou responsáveis discordarem dos professores e funcionários da escola, quanto se a escola deveria ajudar na formação dos hábitos alimentares das crianças, ambos acreditam que a EAN deveria ser trabalhada na escola através de aulas (utilizando a fala, palestras, aulas expositivas sobre a função dos alimentos/nutrientes) ministradas por pessoas com conhecimento de causa, como o nutricionista por exemplo.

Alguns adultos também consideram que a família é a maior responsável pela saúde da criança e que a escola teria um papel secundário. Porém, esta concepção vai contra a tendência atual onde os alunos passam a maior parte do tempo nas instituições de ensino. Ou seja, pensando na lógica da promoção da saúde a escola tem grande importância na saúde dos jovens. Seria interessante, para os membros desta comunidade escolar, considerar escola e família como instituições parcerias e igualmente responsáveis por suas crianças. Esta concepção poderia contribuir para diminuir as discussões sobre quem é mais ou menos responsável ou culpado, de um lado a escola que quer apenas escolarizar e de outro a família com dificuldade para educar. A aproximação entre escola e família parece ser o caminho para superar as dificuldades de ambas as partes e facilitar suas ações, entre elas as ações voltadas à saúde e a EAN.

Entre os adultos que participaram desta pesquisa a maior parte reconhece a relação entre educação, alimentação e saúde. Para estes adultos criança saudável é 
aquele que não adoece, e, criança educada é aquele se segue à risca as normas e regras determinadas pelos adultos. Neste sentido, a crença de que as preferências alimentares das crianças é fruto de características naturais, apenas reforça a necessidade dos adultos de intervir e decidir por eles, uma vez que as crianças não teriam capacidade de escolher o melhor para elas. Este contexto reproduz a educação bancária criticada na obra de Paulo Freire, e impede que a criança desenvolva sua autonomia na hora de fazer suas escolhas alimentares e de zelar por sua saúde.

Alguns adultos consideram que cuidar da saúde é levar a criança ao médico, hospital ou dar suporte à criança durante um período de adoecimento. Na década de 1940, a Organização Mundial da Saúde (OMS), órgão integrante da Organização das Nações Unidas (ONU), definiu saúde como sendo "a busca de um estado completo de bem-estar físico, mental e social, e não apenas a ausência de doença” (OPAS, 1938). Trata-se de um conceito que, apesar de criticado por sua abrangência, representa uma importante ruptura com a visão da saúde enquanto mera "ausência de doença". Essa alteração, que exige que se reconheça o homem como membro de uma sociedade nos leva ao encontro da utopia descrita por Paulo Freire (1979).

Ao observar os projetos da escola (PMU, 2016), em conformidade com o Plano de Gestão da Educação Municipal: 2013-2016, da Secretaria Municipal de Educação (SEMED), a escola possui cinco programas. No nosso entendimento, a EAN poderia fazer parte de pelo menos três deles: no Programa de Formação Continuada, seria possível criar espaços para formações que orientem os professores para trabalhar a EAN de forma transversal; no programa Práticas Pedagógicas e Avaliação, a EAN poderia ter espaço nas atividades dos alunos do Tempo Integral, para as crianças da Educação Infantil, jornada ampliada, TICS no cotidiano escolar, Cinema na escola, A leitura nossa de cada dia, Educação ambiental e outras tantas atividades, utilizando, por exemplo, a horta da escola. Também no programa Rede de Proteção Sociocultural a EAN encontraria espaço nas atividades do programa Saúde na escola e educação ambiental.

Enfim, fazendo uma breve análise do PPP da escola, fica a sensação de que existe espaço, tanto em infraestrutura quanto conceitual para realização de atividades voltadas à EAN. Na prática, contudo, a realização destas atividades acaba dependendo da sensibilidade de cada professor para a temática, o que, por si só, não é o suficiente, já que capacidade e disponibilidade são fatores que não dependem apenas da compreensão e da vontade do docente. É preciso mais. 
As constatações deste estudo falam a favor de membros de uma comunidade escolar, que podem guardar ou não relações com outras comunidades, o que reforça a necessidade de mais pesquisas para ampliar o número de comunidades e o aprofundamento das questões apontadas nestas linhas.

\section{REFERÊNCIAS}

ABREU-BERNARDES, S.T.A.; MÁRQUES, F.T.; BATISTA, G.A. Um relato sobre as produções no Triângulo Mineiro. Inter-Ação, Goiânia, v. 38, n. 1, p. 129-143, jan./abr. 2013. Disponível em: https://revistas.ufg.br/interacao/article/viewFile/25154/15123. Acesso em: 10 jul. 2016.

BARDIN, L. Análise de conteúdo. Lisboa, Edições 70, 1977.

BOOG, M. C. F. Educação nutricional em serviços públicos de saúde. Cad. Saúde Pública, Rio de Janeiro, v.15, Supl. 2, p.139-147, 1999. Disponível em: http://www.scielosp.org/pdf/csp/v15s2/1295.pdf. Acesso em: 20 nov. 2016.

BRASIL. Câmara Interministerial de Segurança Alimentar e Nutricional (CAISAN). Plano Nacional de Segurança Alimentar e Nutricional: Brasília, 2011. Disponível em: http://www.mds.gov.br/segurancaalimentar/publicacoes/livros/plano-nacional-deseguranca-alimentar-e-nutricional-2012-2015/plano-nacional-de-seguranca-alimentar-enutricional-2012-2015. Acesso em: 12 nov. 2017.

CASTRO, J. B. P. et al. "Faça o que eu digo, mas não faça o que eu faço!": a décalage como ferramenta para compreensão de práticas corporais e alimentares. Revista de Nutrição, v. 28, n. 1, p. 99-108, 2015.

FIORI, E. M. Textos escolhidos: educação e política. Porto Alegre: L\&PM, v. 2, 1992.

FREIRE P. Conscientização: teoria e prática da libertação. São Paulo: Cortez \& Moraes, 1979.

FREIRE, P. Pedagogia do oprimido, 17a. ed., Rio de Janeiro: Paz e Terra, 1987.

FREIRE, P. Pedagogia da autonomia: saberes necessários à prática educativa. São Paulo: Paz e Terra, 2004.

GRAMSCI, A. Cadernos do cárcere. (Edição de C. N. Coutinho et al). Rio de Janeiro, Civilização Brasileira, v.6, 2002.

MÁRQUES, F.T.; TALARICO, B.S.L.U. Da comunicação popular à Educomunicação: reflexões no campo da "educação como cultura". Atos de Pesquisa em Educação (FURB), vol. 11, n. 2, p. 422-443, ago.-nov/2016.

OPAS. Escuelas promotoras de la salud: entornos saludables y mejor salud para las generaciones futuras. Washington, 1998, 32p. Disponível em: 
http://bases.bireme.br/cgi-

bin/wxislind.exe/iah/online/?IsisScript=iah/iah.xis\&src=google \&base=REPIDISCA\&la ng $=$ p\&nextAction=lnk\&exprSearch=45661\&indexSearch=ID. Acesso em: 25 out.

2016.

PREFEITURA MUNICIPAL DE UBERABA. Projeto Político-Pedagógico da Escola

Municipal X. Secretaria Municipal de Educação e Cultura de Uberaba. 2016.

UBERABA. Lei n. 8.931 dispõe sobre o Programa Municipal de Educação Alimentar e Nutricional e contém outras disposições. Câmara Municipal de Uberaba. Uberaba/MG, 15 de outubro de 2003.

UBERABA. A Educação no Município de Uberaba. Secretaria Municipal de Educação. Prefeitura Municipal de Uberaba 2016. Disponível em:

http://www.uberaba.mg.gov.br/portal/conteudo,9173. Acesso em: 27 Ago. 2016.

VALENTE, F.L.S. Segurança alimentar e nutricional: transformando natureza em gente. Direito à alimentação: desafios e conquistas. São Paulo: Cortez, p. 103-36, 2002.

\section{Como referenciar este artigo}

CASTRO, R. Educação alimentar e nutricional enquanto processo educativo: um estudo de práticas e percepções de uma comunidade escolar de Uberaba-MG. Temas em Educ. e Saúde, Araraquara, v. 14, n. 2, p. 215-228, jul./dez., 2018. e-ISSN 2526-3471. DOI: 10.26673/tes.v14i2.11690

Submetido em: $14 / 07 / 2018$

Aprovado em: 15/10/2018 